\title{
El neerlandés también existe
}

\section{Dutch really exists}

\author{
Goedele De Sterck y Anna VermeULEN \\ Universidad de Salamanca/Universiteit Gent \\ desterck@usal.es/ anna.vermeulen@ugent.be
}

Según el Eurobarómetro Especial 386: Los europeos y sus lenguas (2012), la lengua materna más hablada en la Unión Europea es el alemán (16\%), seguido del italiano y del inglés (13\%), el francés (12\%), el español y el polaco (8\%). Su mero peso demográfico las convierte automáticamente en lenguas "grandes». En comparación con ellas, las demás lenguas europeas estarán siempre "en minoría», por mucho que las instituciones europeas se empeñen en tratar en pie de igualdad a las 24 lenguas oficiales habladas en sus 28 Estados miembros.

Por ello es de agradecer que la revista Clina se haya comprometido a dar visibilidad a una lengua como la neerlandesa que, al igual que sus hermanas también «minoritarias", pugna por hacerse oír en una escena europea (no digamos ya mundial) en la que impera la ley del más fuerte (y más numeroso).

Si partimos del hecho de que alrededor de 25 millones de personas tienen el neerlandés como lengua materna, podemos concluir que a escala europea y global se trata de una gran lengua minoritaria. Es la lengua oficial de los Países Bajos (junto con el frisón en Frisia), donde comúnmente se denomina «holandés» por metonimia, en referencia al prestigio económico, científico y cultural del que gozaba la provincia de Holanda durante el llamado Siglo de Oro holandés (s. XVII). El neerlandés también es lengua oficial en Bélgica (junto con el francés y el alemán). Popularmente, no así en los documentos oficiales, la variedad belga se conoce como «flamenco», en alusión a Flandes, la región que se extiende al norte de la frontera lingüística neerlandés-francés, 
fijada en 1963. Fuera de Europa, el neerlandés es lengua oficial en Surinam, Aruba, Curazao y San Martín.

En este número de Clina se reflexiona sobre el estado actual del neerlandés y su situación en Europa y el mundo, se presenta una nueva herramienta terminológica bilingüe neerlandés-español, se comentan los obstáculos que dificultan la publicación de una obra literaria traducida de una lengua minoritaria a otra mayoritaria, se comparan tres traducciones al español de un mismo autor realizadas por tres traductores diferentes, y se describen las competencias que no deben faltar en una formación universitaria de traductores e intérpretes.

A modo de introducción, De Swaan dibuja el panorama del neerlandés como lengua oficial de varios Estados en los que este idioma se usa tanto en la vida política y económica como en los círculos académicos, a pesar de la supremacía del inglés. A continuación, Vanden Bulcke y De Groote presentan su recién estrenado banco de datos de terminología jurídica bilingüe neerlandés-español, llamado JuriGenT. En su artículo, las autoras describen las posturas teóricas en materia de traducción (Nord y Šarčević) y terminología (Cabré y Temmerman) en las que se apoya el banco de datos y detallan los criterios que han tenido en cuenta a la hora de elaborar las fichas terminológicas. De Man esboza los desafíos y dificultades a los que se enfrentan los traductores (en este caso anglófonos) a la hora de buscar un editor dispuesto a arriesgarse a publicar una novela escrita en una lengua minoritaria. En su contribución, Humblé se basa en la lingüística de corpus (densidad léxica y número de oraciones) para comprobar si los rasgos estilísticos de un escritor migrante que escribe en neerlandés se mantienen en las traducciones al español. El número se cierra con dos artículos que ahondan en la didáctica de la traducción y de la interpretación, respectivamente. Sanz recalca las características específicas del mercado laboral flamenco, insiste en la necesidad de adaptar las clases de traducción neerlandésespañol a las necesidades reales y explica cómo se puede lograr este objetivo en el aula. Por último, Vermeiren se centra en la interpretación bi-activa. Después de repasar los principales problemas que experimentan los alumnos flamencos al interpretar hacia el español, que suele ser su cuarta lengua, la autora presenta una propuesta pedagógica a partir de su propia experiencia y una revisión crítica de la bibliografía existente.

Todas estas contribuciones demuestran que, aun siendo una lengua minoritaria o minorizada, de menor difusión, pequeña, mediana o medio grande, escasamente traducida, poco hablada, periférica o como se la quiera llamar, el neerlandés está vivo y goza de excelente salud, ya sea en el ámbito de la terminología, la traducción literaria o la enseñanza. Es más, incluso parece haberse lanzado a la conquista de las redes sociales. Según el periódico belga De Standaard (18 de diciembre de 2014), pese a su inferioridad numérica, los neerlandófonos son, desde hace tiempo, muy activos en Wikipedia, donde el neerlandés ocupa el séptimo lugar en la lista de lenguas

Goedele DE STERCK y Anna VERMEULEN El neerlandés también existe 
«importantes». En Twitter incluso figura en el sexto lugar, por delante del alemán, el francés o el ruso.

Aunque este número vaya dedicado al neerlandés, pretende ser una muestra de reconocimiento hacia tantas otras lenguas - por no decir casi todas - que también reclaman un lugar bajo el sol. 